\title{
Thymoma-associated nephrotic syndrome: report of seven cases
}

\section{Wei He}

Xiangya Hospital Central South University https://orcid.org/0000-0002-7768-3095

Zhangzhe Peng ( $\sim$ pengzhangzhe@csu.edu.cn)

Hui Xu

Xiangya Hospital Central South University

Yu Xiao

Xiangya Hospital Central South University

\section{Research article}

Keywords: Thymoma, nephrotic syndrome

Posted Date: December 23rd, 2019

DOI: https://doi.org/10.21203/rs.2.19513/v1

License: @) (i) This work is licensed under a Creative Commons Attribution 4.0 International License. Read Full License 


\section{Abstract}

Background: Thymoma is often associated with a series of paraneoplastic syndromes. Among them, thymoma-related nephrotic syndrome is much rare.

Methods: This retrospective study collected data from patients with thymoma and renal involvement in Xiangya Hospital, Central South University in a period of 5 years to investigate the clinical characteristics of thymoma-associated nephrotic syndrome.

Results: Seven patients were studied (age: $51.1 \pm 21.4$ years old; male/female ratio: 5/2). Among them, thymic pathology revealed 2 cases of type A and 1 case of type B3, myasthenia gravis (MG) was found in 1 out of 7 cases. Renal pathology showed 2 cases of FSGS and 1 case of IgA nephropathy. 2 out of 7 cases who received combined therapy of steroid and immunosuppressive drugs achieved complete remission. Despite 3 out of 7 cases received surgical excision of thymoma, 2 of them experienced treatment failure in nephrotic syndrome.

Conclusions: nephrotic syndrome can be associated with thymoma. The FSGS is the most frequent thymoma-associated glomerular lesion in this study. IgA nephropathy may be another pathological type in thymoma-associated NS. Despite after surgical excision, long treatment periods with high dosage of steroid combined with immunosuppressants were needed to achieve complete remission.

\section{Background}

The thymus is an important central immune organ with important immune regulatory functions and is a site for T lymphocyte differentiation and maturation. Thymoma/thymic hyperplasia are often associated with multiple paraneoplastic syndromes, such as myasthenia gravis (MG), pure red-cell aplasia, systemic lupus erythematosus and pemphigus vulgaris ${ }^{[1]}$. Among them, the incidence of thymoma-associated glomerular diseases is very low, about $2 \%{ }^{[2]}$, which may easily be ignored. Among the glomerular diseases, about $77 \%$ of them may presented as nephrotic syndrome (NS). Thymoma-associated NS may appear before, after or at the same time as the primary tumor, or after thymectomy for a period of time $\mathrm{e}^{[3-5]}$.

Nowadays, it is believed that the occurrence of NS may be related to the presence of microthymoma or immune regulation disorder after thymectomy[6] insufficient expression of thymic autoimmune regulator (AIRE) and $\mathrm{MHC}$ class II may be another reason for the occurrence of paraneoplastic syndromes ${ }^{[7]}$. The pathological changes of the kidney are most common in minimal change disease (MCD), followed by membranous nephropathy (MN), anti-neutrophil cytoplasm antibody (ANCA)-related crescentic glomerulonephritis, focal segmental glomerular sclerosis (FSGS), and thrombotic microangiopathy ${ }^{[3 ;}$; . Antitumor therapy is the cornerstone of the treatment of thymoma-associated glomerular disease ${ }^{[3 ;}$; . However, in clinical practice, treatment for thymoma/thymic hyperplasia combined with NS is difficult due to many patients are often complicated with infection, severe hypoalbuminemia, thrombosis, and acute kidney injury, and are difficult to tolerate surgery, radiation and chemotherapy. Moreover, the correlation between the clinical features and pathological type of thymoma and NS should be further eliminated.

The aim of this retrospective study was to identify such cases, diagnosed with thymoma/thymic hyperplasia and NS, and to investigate the clinical characteristics of thymoma-related NS in a Chinese population. Renal and thymic pathology were reviewed to understand the link between thymic T-cell production dysregulation and the induction of nephropathy.

\section{Methods}

1. Clinical data: including gender, age at diagnosed with NS, renal biopsy and thymoma, histological type, clinical stage, therapeutic schedule, and whether thymoma is accompanied by other paraneoplastic syndrome.

2. Laboratory examination: including renal pathological type, proteinuria in $24 \mathrm{~h}$, serum albumin (Alb), serumcreatinine (Scr), hemoglobin (Hb), anti-nuclear antibody (ANA), anti-dsDNA antibody, anti-soluble nuclear antigen (ENA) antibody, blood and urine immunofixation electrophoresis (IFE), serum m-type phospholipase $\mathrm{A} 2$ receptor (PLA2R) antibody.

3. Pathological examination of kidney: the deposition of $\operatorname{lgG}, \lg A$, IgM, C3, Clq, fibrin-related antigen and PLA2R were detected by immunofluorescence after conventional processing of biopsy specimens. Pathological changes of renal tissues were observed by light microscope (HE, PASM and Masson staining) and electron microscope.

4. Treatment and outcome: the follow-up time started from the time of renal biopsy, and the patient's treatment regimen, proteinuria, blood serum Alb, Scr and other indicators were recorded.

5. Definitions: (1) Classification of thymoma pathology was used the WHO thymic tumors' classification criteria (2004) ${ }^{[10]}$. With this criterion, thymoma was classified into Type A, AB, B (B1,B2,B3) and C. (2) Clinical stage was used the Masaoka clinical stage of thymoma ${ }^{[11]}$, which was classified into stage I, Ila, Ilb, III, IVa and IVb. (3) Diagnostic criteria of NS: serum Alb $<30 \mathrm{~g} / \mathrm{L}$ and proteinuria $>3.5 \mathrm{~g} / 24 \mathrm{~h}$. Efficacy evaluation criteria of treatment: complete remission (CR) was defined as proteinuria $<0.3 \mathrm{~g} / 24 \mathrm{~h}$. Proteinuria in $24 \mathrm{~h}$ decreased $\geq 50 \%$ from baseline and $<3.5 \mathrm{~g} / 24 \mathrm{~h}$ were defined as partial remission (PR). Proteinuria in $24 \mathrm{~h}$ decreased $<50 \%$ from baseline, or $>3.5 \mathrm{~g} / 24 \mathrm{~h}$ was defined as treatment failure.

\section{Results}

1. Basic data (Details are shown in table 2): among the 7 patients ( 5 males and 2 females), male: female $=2.5: 1$, the average age of NS was $51.1 \pm 21.4$ years. Among them, 4 patients found NS and thymoma simultaneously, and the remaining 3 patients were: Case 3 presented NS before thymoma was found. NS was reported in the second month after thymectomy in case 4 . Case 7 presented with thymoma and MG at the same time. The median follow up was 80 months. 
2. Nephrotic syndrome: Of all the 7 patients, proteinuria ranged from 3.78 to $16.94 \mathrm{~g} / 24 \mathrm{~h}$ and serum Alb ranged from 13.7 to $28.7 \mathrm{~g} / \mathrm{L}$, meeting the diagnostic criteria of NS. Other complications including infection (5/7), anemia (3/7), hypertension (5/7), thromboembolic event (1/7), serological examination revealed that lgG level in three patients decreased, which may be associated with NS. 2 patients were positive with low ANA titer, 2 patients were positive with high ANA titer but negative with dsDNA antibodies, which did not meet the diagnostic criteria of systemic lupus erythematosus. Serum anti-PLA2R antibody was negative in all patients, and no monoclonal immunoglobulin was found in hematuria immunofixation electrophoresis (Details are shown in table 2).

3. Pathology of kidney: 3 patients received renal biopsy. Among them, case 2 was FSGS (apex type), case 3 was FSGS, and case 6 was IgA nephropathy (IgAN) (M1E0S0T0, Lee's classification grade II). 3 patients had tubular injury (Figure 1).

4. Thymus pathology: 3 patients underwent surgical excision, and the pathological types were as follows: Case 2 was type $\mathrm{A}$ (WHO classification), Masaoka clinical stage I; Case 3 was type A, Masaoka clinical stage Ilb; Case 4 was type B3, Masaoka clinical stage I, and both the 3 cases did not accept postoperative chemoradiotherapy.

5. Clinical outcome: Among 7 patients, cases 1 and 6 were complete remission; Cases 3 and 5 showed partial remission; Cases 2, 4 and 7 were not alleviated. Case 1 received prednisone $30 \mathrm{mg}$ per day, tacrolimus $2 \mathrm{mg}$ per day and followed by a progressive tapering of the dose for one year, and finally achieved complete remission; Case 2 was admitted into our department because of NS, and his renal pathology revealed FSGS. In the period of curing NS, we found thymoma. Because the patient's serum albumin is very low, it's impossible to perform thymectomy, and after a series of hemodialysis, the patient's edema became a bit better, after prednisone $25 \mathrm{mg}$ per day for one month, then prednisone $20 \mathrm{mg}$ per day and tacrolimus $1.5 \mathrm{mg}$ per day for 4 months, his serum albumin increased from $15.9 \mathrm{~g} / \mathrm{L}$ to $22.3 \mathrm{~g} / \mathrm{L}$, then the patient received surgical excision. Until we finished this paper, the patient's symptoms did not relieve much; case 3 received prednisolone $10 \mathrm{mg}$ per day and tacrolimus $1 \mathrm{mg}$ per day for one year, then the treatment protocol was changed into prednisolone $10 \mathrm{mg}$ tertian day and azathioprine $100 \mathrm{mg}$ per day till now and the symptoms were partially relieved. Case 4 were treated with methylprednisolone $8 \mathrm{mg}$ per day after thymectomy for half a year, and the symptoms were not relieved. For case 5 , the symptoms were partially relieved after $50 \mathrm{mg}$ prednisone for 8 months. In case 6 , the result of renal biopsy was IgA nephropathy, and the symptoms were completely relieved after prednisone $30 \mathrm{mg}$ per day and followed by a progressive tapering of the dose for 9 months. In case 7, due to the severe symptoms of myasthenia gravis, the patient's symptoms improved after plasmapheresis, and the patient was given azathioprine $25 \mathrm{mg}$ twice per day for immunosuppressive therapy for 2 months, but the symptoms did not relieve (Details are shown in table 2).

\section{Discussion}

Thymoma often happened insidiously and is often missed because of lack of direct tumor's invasive symptoms. In our study, approximately 57.1\% (4/7) patients were found to have thymoma during the diagnosis and treatment of NS. Karras analyzed 21 patients with thymoma-associated nephropathy, of which $47.6 \%$ (10/21) presented with nephropathy several months or years after diagnosis and treatment of thymic disease (mean interval: $108 \pm 83$ months; Range 8-180 months), only $23.8 \%$ (5/21) patients diagnosed both renal disease and thymoma simultaneously ${ }^{[3]}$. Davison's study found that about $40 \%$ of patients with NS are often preceded the diagnosis of malignancy ${ }^{[12]}$. Due to small number of cases enrolled, only 1 patient with NS prior to thymoma was found in this study. As NS is often characterized by hypoproteinemia and edema of bilateral lower limbs, it is more likely to be discovered. Therefore, it is particularly necessary to perform chest CT scan when screening and diagnosing the etiology of NS.

Abnormal thymic tissue can lead to regulatory disorders produced by T cells: AIRE deficiency, decreased MHC II expression, decreased Tregs, autoantibodies against I interferons, abnormally high CD $8+C D 45 R A+T$ cells and cytokines for age were the possible underlying mechanism ${ }^{[13 ; 14]}$. On the other hand, the occurrence of thymoma itself can alter the thymic architecture, which may disrupt regional immune microenvironment, and lead to immature autoactive $T$ cell activation which can escape negative selection in the thymus and further evade peripheral tolerance mechanism ${ }^{[15]}$. This autoimmune response and immune compounds can thereby increase the permeability of glomeruli, leading to the occurrence of $\mathrm{NS}^{[3]}$.

Previous studies have shown that minimal-change nephropathy is the most common nephropathy caused by thymoma, followed by membranous nephropathy, and also includes focal segmental glomerular sclerosis ${ }^{[3]}$. Posner first reported a case of thymic carcinoma with membranous glomerulonephritis in $1980^{[16]}$. Jhaveri's study found that membranous nephropathy is a common type of renal pathology associated with solid tumors ${ }^{[2]}$. In our study, 2 of the 3 patients with biopsy were FSGS and 1 was IgA nephropathy. The possible reason may be: among the 21 patients analyzed by Karras, 14 patients' thymus underwent pathological reassessment, according to WHO grading standards, the thymus pathology were as follows: $B 2(n=7)$, AB $(n=4)$, B3 $(n=2)$ and C $(n=1)$. According to the Masaoka stage, 12 cases were stage III or IV (7 cases for stage III; 5 cases for stage IV). While in our study, two cases were type A, Masaoka clinical stage I and Ilb respectively. One case was type B3 and Masaoka clinical stage I. The thymus pathology type was different from that of Karras's study, which may be the reason for the inconsistency of the two types of renal pathology. We speculated that different types of thymopathologic type may lead to different types of renal pathology. The other reason may be, for 4,910 patients who received renal biopsies in China, the most common forms of primary glomerulonephritis were membranous nephropathy (MN,37.2\%) and IgA nephropathy (IgAN,29.9\%) ${ }^{[17]}$. With the same study area of Karras' study, Simon's study showed that the most common primary glomerular diseases was also IgAN (2.4/1000, 3.6/1000 in males and 1.3/1000 in females) in 898 patients in a region of France ${ }^{[18]}$. While, in Karras' study, there is no case of IgA, which may be associated with bias or renal pathology related to thymic pathology type. This study demonstrated for the first time that IgA nephropathy may be a new pathological type in thymoma-associated NS.

There is no standard treatment protocol about the dosage and duration of steroid and/or immunosuppressants of thymoma-associated NS. Adequate duration of steroids combined with immunosuppressants are more effective than steroids only in treating NS, whether or not the thymus is removed. In karras's study, 11 out of 13 patients presented with MCD or FSGS were initially treated with steroids, the effective rate was $84 \%$ (54\% CR, $30 \% \mathrm{PR})^{[3]}$, but in our study, even by combining steroid, immunosuppressants and thymectomy, the effective rate is only $57 \%$ (4/7). Immunosupressive drugs, such as cyclosporine, 
cyclophosphamide, chlorambucil, and azathioprine, are the common choice ${ }^{[3 ; 19]}$. In our study, we chose tacrolimus, a more powerful and new immunosuppressive agents, to suppress the immune function, and the patients (2/2) achieved partial remission.

A short combination therapy, insufficient dosage of steroid and/or immunosuppressants and persistent existence of the primary etiology may be the fail reason of case 2, 4 and 7. On the other hand, Shin Hye Yoo reported a patient with metastatic thymoma accompanied by NS (surgical staging: Masaoka stage IVa, World Health Organization type B3), which is the same WHO classification stage of case 4, with 6 cycles of chemotherapy and removal of left diaphragm, left pleura and anterior thymomectomy, the patient achieved complete remission, and no signs of recurrence of thymoma and NS were observed after that ${ }^{[20]}$. For those who underwent surgical excision in our study, only case 3 achieved CR, but for those who did not undergo surgical excision, the treatment in 3 out of 4 patients were effective. With limited data, we were unable to identify the absolute correlation between thymomectomy and the remission of NS, but we can ascertain that combination therapy (combing steroids, immunosuppressants and thymectomy) may be effective way to reduce proteinuria.

In the course of the treatment of NS, most patients were admitted into our department because of lower extremity edema, anemia and infection. In the routine examination after admission, we found thymoma occasionally. Due to the existence of infection, severe hypoalbuminemia, perinephric effusion, or with the use of steroid and /or immunosuppressants, it will increase the possibility of infection, severely postpone the operation of thymoma. It also explained why the cases of thymectomy were less in this study.

\section{Conclusion}

In conclusion, in this study, we demonstrated that FSGS is the most frequent thymoma-associated glomerular lesion. IgA nephropathy may be a new pathological type in thymoma-associated NS. Combination therapy may be an effective way to achieve complete remission for both thymoma and NS. The effect of thymectomy upon renal symptoms is difficult to ascertain. Standardized, unified and effective treatment protocol should be exerted to relieve misery of these patients.

\section{Declarations}

\section{Ethics approval and consent to participate}

This study was approved by the medical ethics committee of Xiangya Hospital, Central South University. All participants or their authorized bailors were consent to the study.

\section{Consent for publication}

All participants or their authorized bailors were consent to the study's publication.

\section{Availability of data and material}

None.

\section{Competing interests}

The authors declared they do not have anything to disclose regarding conflict of interest with respect to this manuscript.

\section{Funding}

None.

\section{Authors' contributions}

WH and ZP involved in the study design. WH and YX were responsible for data collection and analysis. WH wrote the manuscript. ZP and HX modified and revised the manuscript. All authors have read and approved the final version of the manuscript.

\section{Acknowledgements}

None.

\section{Abbreviations}

MG myasthenia gravis

NS nephrotic syndrome

AIRE autoimmune regulator

MCD minimal change disease

MN membranous nephropathy 
ANCA anti-neutrophil cytoplasm antibody

FSGS focal segmental glomerular sclerosis

Alb albumin

Scr serum creatinine

$\mathrm{Hb}$ hemoglobin

ANA anti-nuclear antibody

ENA extractable nuclear antigen

IFE immunofixation electrophoresis

PLA2R phospholipase A2 receptor

CR complete remission

PR partial remission

$\lg$ AN IgA nephropathy

\section{References}

[1] Thomas, C. R., Wright, C. D., \& Loehrer, P. J. 1999. Thymoma: state of the art. J Clin Oncol, 17(7), 2280-2289. doi: 10.1200/JC0.1999.17.7.2280

[2] Jhaveri, K. D., Shah, H. H., Calderon, K., Campenot, E. S., \& Radhakrishnan, J. 2013. Glomerular diseases seen with cancer and chemotherapy: a narrative review. Kidney Int, 84(1), 34-44. doi: 10.1038/ki.2012.484

[3] Karras, A., de Montpreville, V., Fakhouri, F., Grünfeld, J. P., \& Lesavre, P. 2005. Renal and thymic pathology in thymoma-associated nephropathy: report of 21 cases and review of the literature. Nephrol. Dial. Transplant., 20(6), 1075-1082.

[4] Kuwata, T., Iwata, T., \& Iwanami, T. 2012. Post-thymectomy myasthenia gravis with an episode of Osserman stage III. J Surg Case Rep, 2012(5), 3. doi: $10.1093 / \mathrm{jscr} / 2012.5 .3$

[5] Nakajima, J., Murakawa, T., Fukami, T., Sano, A., Takamoto, S., \& Ohtsu, H. 2008. Postthymectomy myasthenia gravis: relationship with thymoma and antiacetylcholine receptor antibody. Ann Thorac Surg, 86(3), 941-945. doi: 10.1016/j.athoracsur.2008.04.070

[6] Yamada, Y., Yoshida, S., Iwata, T., et al. 2015. Risk factors for developing postthymectomy myasthenia gravis in thymoma patients. Ann Thorac Surg, 99(3), 1013-1019. doi: 10.1016/j.athoracsur.2014.10.068

[7] Lippner, E. A., Lewis, D. B., Robinson, W. H., \& Katsumoto, T. R. 2019. Paraneoplastic and Therapy-Related Immune Complications in Thymic Malignancies. Curr Treat Options Oncol, 20(7), 62. doi: 10.1007/s11864-019-0661-2

[8] Yamauchi, J., Ubara, Y., \& Suwabe, T. 2011. Focal segmental glomerulosclerosis associated with invasive thymoma. Ther Apher Dial, 15(2), 210-211. doi: 10.1111/j.1744-9987.2010.00871.x

[9] Matsuda, M., Miki, J., Tabata, K., Ikezoe, M., Nishizawa, N., \& Ishigame, H. 2000. Myasthenia gravis with membranous nephropathy, successfully treated with extended total thymectomy. Intern Med, 39(6), 490-494. doi: 10.2169/internalmedicine.39.490

[10] Rena, O., Papalia, E., Maggi, G., et al. 2005. World Health Organization histologic classification: an independent prognostic factor in resected thymomas. Lung Cancer, 50(1), 59-66. doi: 10.1016/j.lungcan.2005.05.009

[11] Masaoka, A., Monden, Y., Nakahara, K., \& Tanioka, T. 1981. Follow-up study of thymomas with special reference to their clinical stages. Cancer, 48(11), 2485-2492. doi: 10.1002/1097-0142(19811201)48:11<2485::aid-cncr2820481123>3.0.co;2-r

[12] Davison, A. M. 2001. Renal diseases associated with malignancies. Nephrol Dial Transplant, 16 Suppl 6, 13-14. doi: 10.1093/ndt/16.suppl_6.13

[13] Kisand, K., Lilic, D., Casanova, J. L., Peterson, P., Meager, A., \& Willcox, N. 2011. Mucocutaneous candidiasis and autoimmunity against cytokines in APECED and thymoma patients: clinical and pathogenetic implications. Eur J Immunol, 41(6), 1517-1527. doi: 10.1002/eji.201041253

[14] Hoffacker, V., Schultz, A., Tiesinga, J. J., et al. 2000. Thymomas alter the T-cell subset composition in the blood: a potential mechanism for thymomaassociated autoimmune disease. Blood, 96(12), 3872-3879.

[15] Weksler, B., \& Lu, B. 2014. Alterations of the immune system in thymic malignancies. J Thorac Oncol, $9(9$ Suppl 2), S137-142. doi: $10.1097 /$ JTO.0000000000000299 
[16] Posner, M. R., Prout, M. N., \& Berk, S. 1980. Thymoma and the nephrotic syndrome: a report of a case. Cancer, 45(2), 387-391. doi: 10.1002/10970142(19800115)45:2<387::aid-cncr2820450233>3.0.co;2-z

[17] Nie, P., Chen, R., Luo, M., et al. 2019. Clinical and Pathological Analysis of 4910 Patients Who Received Renal Biopsies at a Single Center in Northeast China. Biomed Res Int, 2019, 6869179. doi: 10.1155/2019/6869179

[18] Simon, P., Ramee, M. P., Boulahrouz, R., et al. 2004. Epidemiologic data of primary glomerular diseases in western France. Kidney Int, 66(3), 905-908. doi: 10.1111/j.1523-1755.2004.00834.x

[19] Kilis-Pstrusinska, K., Medynska, A., Zwolinska, D., \& Dobaczewski, G. 2008. Lymphoepithelioma-like thymic carcinoma in a 16-year-old boy with nephrotic syndrome-a case report. Pediatr Nephrol, 23(6), 1001-1003. doi: 10.1007/s00467-007-0666-0

[20] Yoo, S. H., Kim, H. J., Kim, J. H., et al. 2017. Nephrotic syndrome associated with metastatic thymoma treated with chemotherapy. Medicine (Baltimore), 96(1), e5408. doi: 10.1097/md.0000000000005408

\section{Tables}

Table 1 Clinical data regarding thymoma

\begin{tabular}{|c|c|c|c|c|c|c|c|}
\hline Patient No. & Gender & Follow up(months) & Age at thymoma & Thymic pathology & Masaoka clinical stage & Thymoma treatment & Associated diseases \\
\hline 1 & $\mathrm{M}$ & 82 & 64 & T-NA & NA & NA & \\
\hline 2 & M & 6 & 59 & T-A & I & surgical excision & \\
\hline & M & 225 & 51 & T-A & IIb & surgice & \\
\hline 4 & $\mathrm{M}$ & 61 & 63 & T-B3 & & surgical excision & \\
\hline & $\mathrm{F}$ & 81 & 41 & NA & NA & & \\
\hline 6 & $\mathrm{~F}$ & 80 & 10 & NA & NA & NA & \\
\hline & $\mathrm{M}$ & 3 & 71 & NA & NA & NA & MG \\
\hline
\end{tabular}

Gender: M, male; F, female.

NA: not available.

Thymic pathology: T, malignant thymoma; 0, no histology; A, AB, B1, B2, B3, C, pathological classification of thymomas according to WHO;

Table 2 Clinical data regarding nephropathy

\begin{tabular}{|c|c|c|c|c|c|c|c|c|c|c|}
\hline $\begin{array}{l}\text { Patient } \\
\text { No. }\end{array}$ & $\begin{array}{c}\text { age at } \\
\text { renal } \\
\text { biopsy }\end{array}$ & $\begin{array}{c}\text { Renal } \\
\text { pathology }\end{array}$ & $\begin{array}{c}\text { Age at } \\
\text { nephropathy }\end{array}$ & $\begin{array}{l}\text { Urine protein } \\
\square \mathrm{g} / 24 \mathrm{~h} \square\end{array}$ & $\begin{array}{l}\text { Serum } \\
\text { Alb } \\
(\mathrm{g} / \mathrm{L})\end{array}$ & $\begin{array}{c}\mathrm{Scr} \\
\text { (umol/L) }\end{array}$ & hemodialysis & steroid & Immunosuppression & Outcome \\
\hline 1 & NA & NA & 64 & 5.38 & 13.7 & 263.4 & $\mathrm{NA}$ & $\begin{array}{c}\text { prednisone 30mg } \\
\text { per day and } \\
\text { followed by a } \\
\text { progressive } \\
\text { tapering of the } \\
\text { dose for one year }\end{array}$ & $\begin{array}{c}\text { tacrolimus 2mg per } \\
\text { day }\end{array}$ & CR \\
\hline 2 & 59 & $\begin{array}{l}\text { FSGS (apex } \\
\text { type) }\end{array}$ & 59 & 16.94 & 15.9 & 296.5 & Yes & $\begin{array}{l}\text { methylprednisolone } \\
\text { sodium succinate } \\
20 \mathrm{mg} \text { per day for } \\
10 \text { days } ₫ \text { prednisone } \\
25 \mathrm{mger} \text { dav }\end{array}$ & $\begin{array}{l}\text { tacrolimus } 1.5 \mathrm{mg} \\
\text { per day. prednisone } \\
20 \mathrm{mg} \text { per day }\end{array}$ & $\mathrm{F}(+\mathrm{S})$ \\
\hline 3 & 51 & FSGS & 46 & 3.78 & 22.5 & 97 & NA & $\begin{array}{l}\text { prednisone } 10 \mathrm{mg} \\
\text { per day }\end{array}$ & tacrolimus 1mg per & $\mathrm{PR}(+\mathrm{S})$ \\
\hline 4 & NA & NA & 63 & 4.12 & 22.3 & 535 & NA & methylprednisolon & & $\mathrm{F}(+\mathrm{S})$ \\
\hline 5 & NA & NA & 41 & 3.80 & 15.1 & 369 & NA & prednisone $50 \mathrm{mg}$ & & PR \\
\hline 6 & 10 & $\begin{array}{c}\text { IgA } \\
\text { nephropathy }\end{array}$ & 10 & 3.95 & 25.4 & 53 & NA & $\begin{array}{l}\text { prednisone } 30 \mathrm{mg} \\
\text { per day and } \\
\text { followed by a } \\
\text { progressive } \\
\text { tapering of the } \\
\text { dose to } 15 \mathrm{mg} \text { per } \\
\text { tertian day }\end{array}$ & & CR \\
\hline 7 & NA & NA & 75 & 4.78 & 28.7 & 99 & plasmapheresis & not used & $\begin{array}{c}\text { azathioprin } 50 \mathrm{mg} \\
\text { per day }\end{array}$ & $\mathrm{F}$ \\
\hline
\end{tabular}

Steroid effect: F, failure; R, relapse at tapering; CR, complete remission; PR, partial remission; in association with surgery $(+\mathrm{S})$, chemotherapy $(+\mathrm{C})$ or radiotherapy $(+\mathrm{R})$ for thymoma. 

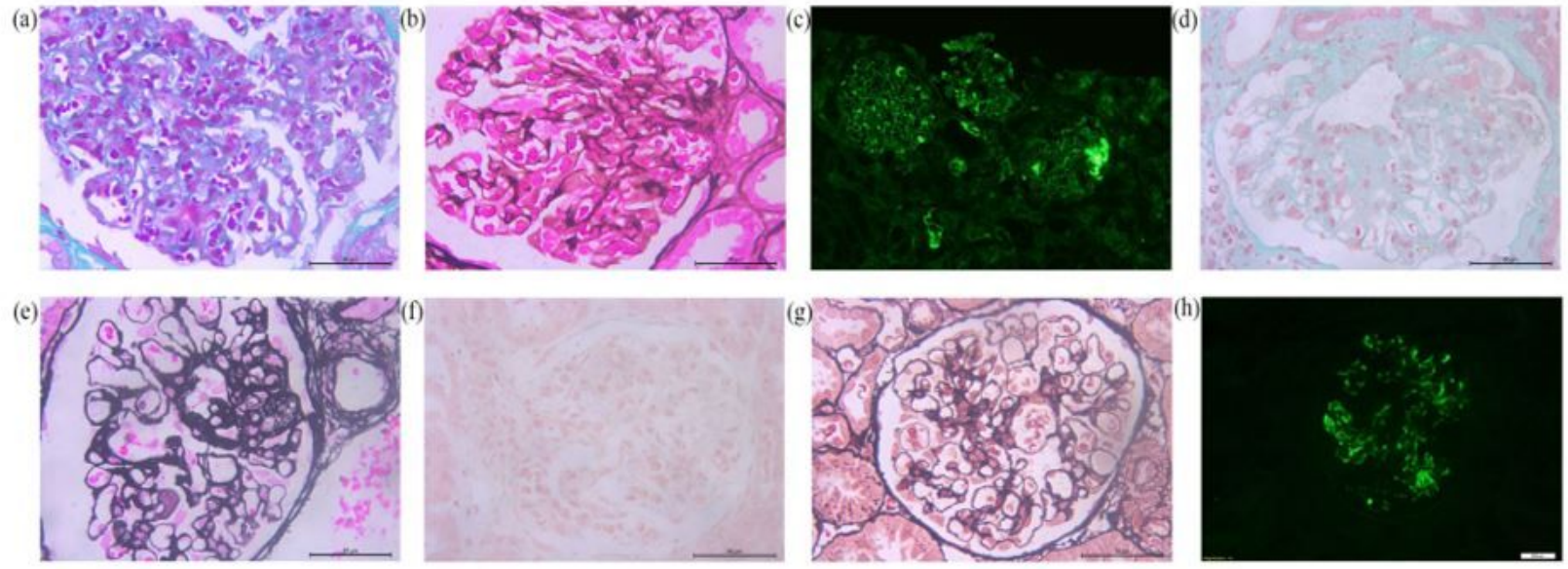

\section{Figure 1}

Figure 1 Pathological changes of renal tissue in patients with thymoma-related nephrotic syndrome: Case 2 (FSGS): (a) Masson staining ( $\left.{ }^{*} 400\right)$, (b) PASM staining (*400), (c) Electron microspcope; Case 3 (FSGS): (d) Masson staining (*400), (e) PASM staining (*400); Case 6 (IgA nephropathy): (f) Masson staining $\left({ }^{\star} 400\right)$, (g) PASM staining $(* 400)$, (h) Electron microspcope 